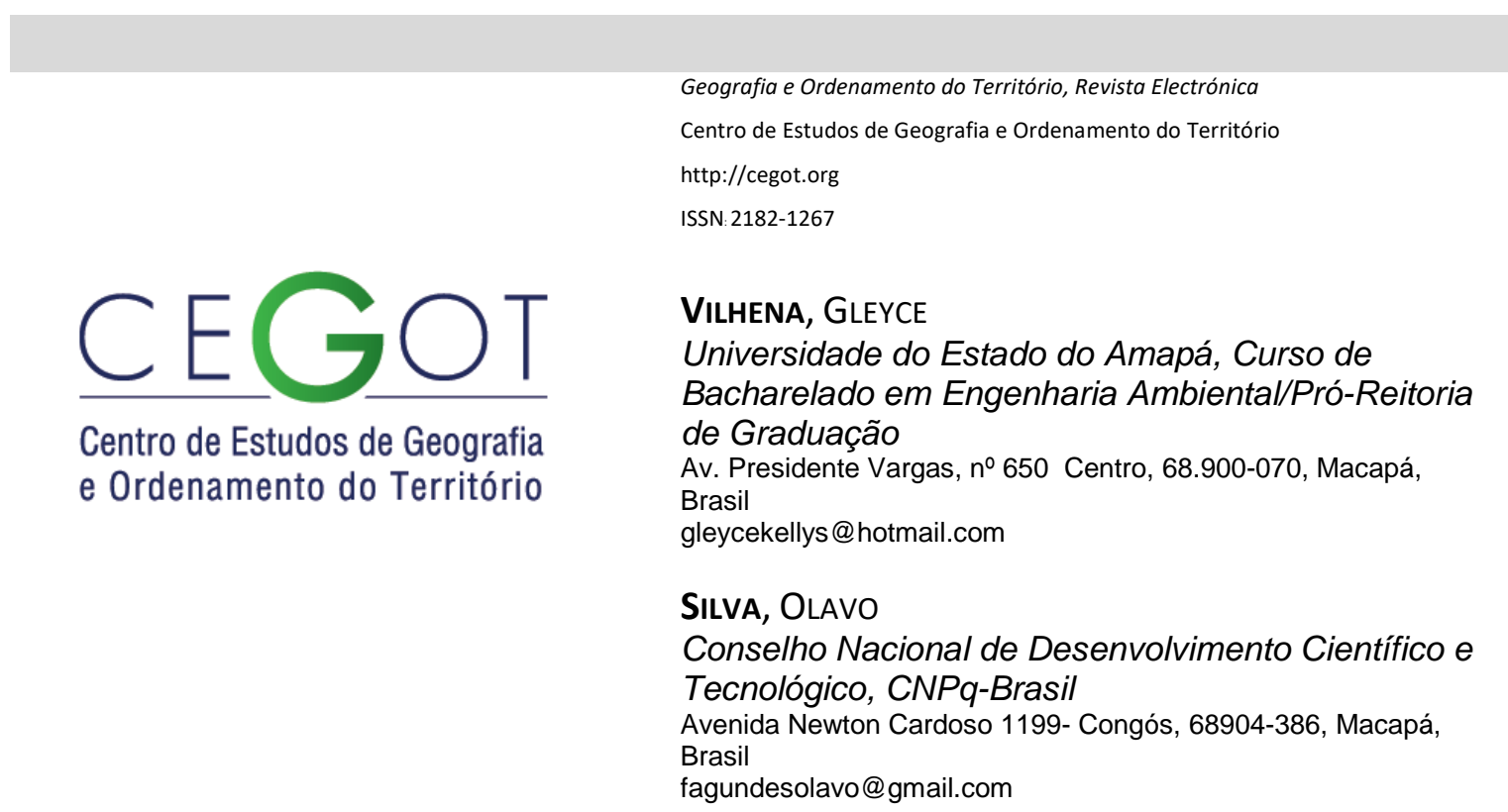

\title{
Avaliação de impactos ambientais de rodovias no Módulo II da Floresta Estadual do Amapá
}

\author{
Evaluation of environmental impacts of roads in Module II of the Amapá State \\ Forest
}

Referência: Vilhena, Gleyce; Silva, Olavo (2017). Avaliação de impactos ambientais de rodovias no Módulo II da Floresta Estadual do Amapá. Revista de Geografia e Ordenamento do Território (GOT), n.o 12 (dezembro). Centro de Estudos de Geografia e Ordenamento do Território, p. 357-381, dx.doi.org/10.17127/got/2017.12.016

\section{RESUMO}

A rede rodoviária no Amapá é fundamental para o desenvolvimento das atividades produtivas nas cadeias extrativistas, florestal e mineral. A Floresta Estadual do Amapá (FLOTA), Unidade de Conservação de uso sustentável, foi implantada visando entre outras atividades, aproveitar o grande potencial dos recursos florestais. Composta de quatro módulos-áre é acessada através de rodovias conectadas aos dois principais eixos rodoviários do Estado, as BR-210 e 156. Esta pesquisa buscou realizar a avaliação dos impactos ambientais causados pela alteraçao do relevo na construção da rodovia de acesso ao entorno do modulo II da FLOTA e elaborar um modelo menos impactante para acesso às areas de manejo florestal. Para a avaliação de impactos utilizou-se o método de sobreposição de cartas com suporte na Matriz de Leopold. Constatou-se que os impactos ambientais causados pela estrada implantada no entorno, apresentam maior magnitude e importância quando comparados aos impactos do modelo de projeto geométrico proposto, elaborado com maior precisão na análise dos elementos do relevo.

Palavras-chaves: Amapá. Rodovias. Relevo. Impactos Ambientais. Sobreposição de Cartas. 


\section{ABSTRACT}

The road network in Amapá is fundamental for the development of productive activities in extractive, forestry and mineral chains. The State Forest of Amapá (FLOTA), a Sustainable Use Conservation Unit, was implemented aiming, among other activities, to take advantage of the great potential of forest resources. Composed of four air-modules, it is accessed through highways connected to the two main roads of the State, BR-210 and 156 . This research sought to carry out the evaluation of the environmental impacts caused by the alteration of the relief in the construction of the access highway to the surroundings of the module II of FLOTA and to elaborate a model less impacting for access to the areas of forest management. For the evaluation of impacts, the method of overlapping charts with support in the Leopold Matrix was used. It was verified that the environmental impacts caused by the road implanted in the surroundings, are of greater magnitude and importance when compared to the impacts of the proposed geometric design model, elaborated with greater precision in the analysis of the elements of the relief.

Key words: Amapá. Highways. Relief. Environmental impacts. Card Overlay.

\section{Introdução}

A consolidação do Estado nacional brasileiro na área que hoje configura o estado do Amapá foi em grande medida, resultado de ações institucionais do governo federal. Essas ações visaram principalmente a defesa do território amazônico face ao vazio demográfico. Historicamente as atividades econômicas de maior destaque no Amapá estiveram relacionadas à extração de seus recursos naturais, tais como madeira, pescados e minérios. Essas atividades incentivaram a atração de investimentos externos importantes no processo de ocupação, integração e organização do espaço amapaense, transformado em Território Federal do Amapá em 1943 (COSMO, 2007).

Durante as décadas de 1950-1970, o crescimento demográfico do Amapá e a sua organização espacial, estiveram intimamente relacionados ao processo de exploração $e$ exportação do manganês. No período de 1980-1996, ocorreu a reorganização do território com a criação de novos municípios e a transformação do Amapá em Estado. Nesse período também ocorreu a diversificação das atividades produtivas com o início da exploração mineral do ouro em Tartarugalzinho e Calçoene e a implantação da Área de Livre Comércio de Macapá e Santana. Essas dinâmicas territoriais também levaram à reorganização dos espaços urbanos, consolidando a polorarização da área metropolitana formada pela capital Macapá e a cidade portuária de Santana. (PORTO, 2006). 
A dinâmica de desenvolvimento regional baseada no extrativismo mineiral conjugada a um novo modelo de extrativismo florestal ajudou a impulsionar a evolução da infraestrutura do sistema viário no Amapá. Ao longo da primeira metade do século $\mathrm{XX}$, internamente, $\mathrm{o}$ território amapaense sempre foi relativamente isolado por via terrestre, dada a precariedade das rodovias que não passavam de grandes trilhas abertas sobre o solo. Segundo Silva e Cunha (2016), pode-se afirmar, pelas mudanças que implantou, que a exploração de manganês em Serra do Navio, em finais da década de 50 do século XX, foi a dinâmica de desenvolvimento regional que mais impactou o sistema viário amapaense. $A$ partir dessa dinâmica os fluxos internos deixam de ser preponderantemente feitos pelo modal aquaviário e passam a se concentrar nos modais rodoviário e ferroviário. A implantação da estrada de ferro em conjunto com as BR 210 e 156 ajudaram na melhoria das conexões e do os fluxos internos impulsionando novas rotas e destinos.

A implantação do extrativismo mineral em escala industrial impôs mudanças gradativas na dinâmica dos fluxos internos. A partir da BR-156 foi implantada uma rede de pequenas rodovias que foi base para a silvicultura do pinus, posteriormente substituído pelo eucalipto. Essa atividade de base extrativa florestal surgiria como expansão do processo produtivo mineral, sendo a empresa Amapá Florestal e Celulose ligada à controladora da Indústria de Comércio e Minérios S/A(ICOMI). Por estar fortemente atrelado ao processo produtivo nas cadeias extrativistas, o sistema de transportes terrestres no Amapá, formatou um processo de integração regional dependente dessas atividades (SILVA e CUNHA, 2016).

Com o recente fomento à exploração dos recursos florestais no Módulo II da FLOTA o sistema rodoviário deverá ter acréscimo de novas estradas. Nessa região, a difícil condição de navegabilidade dos altos cursos dos rios impede o escoamento da produção por via fluvial. Dada a importancia do sistema rodoviário para a extração florestal a ser efetuada e a necessidade de novas vias de acesso, este trabalho procurou investigar como a alteração do relevo para a abertura de rodovias na região impacta o meio ambiente? Como objetivos estipulou-se estudas as alterações efetuadas no relevo para a implantação da via de acesso ao entorno do Módulo II. Também se estipulou projetar um modelo de rodovia que possa minimizar as alterações no processo de ampliação da rede rodoviária que deverá servir de suporte ao processo produtivo. 


\section{1. Área de estudo}

A pesquisa teve como área foco o módulo II da Floresta Estadual do Amapá (FLOTA) e seu entorno. A FLOTA é uma Unidade de Conservação de Uso sustentável que integra o Sistema Estadual de Unidade de Conservação do Amapá e possui uma área de aproximdamente $23.000 \mathrm{~km}^{2}$. No módulo II foram criadas três Unidades de Manejo Florestal (UMF) com aproximadamente $1240 \mathrm{~km}^{2}$, para exploração dos recursos florestais (Figura 1). Essas UMF compreendem um polígono no centro da área que está situada no centro-oeste do estado, com duas pequenas porções abrangendo o oeste do município de Porto Grande e a parte sul do município de Pedra Branca do Amaparí. A maior porção da área total das Unidades de Manejo do módulo II da FLOTA está situada ao norte do município de Mazagão.

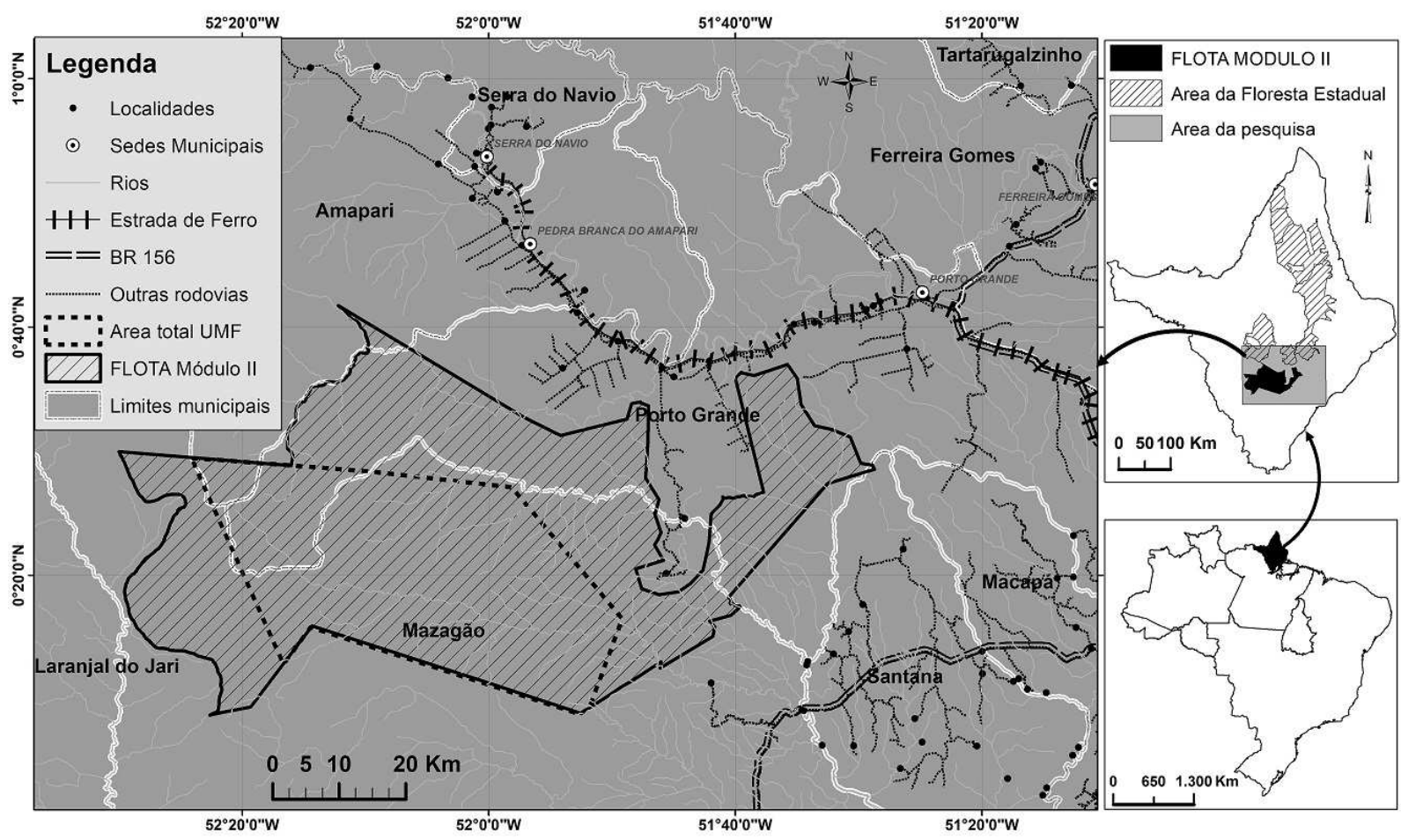

Figura 1: Localização do Módulo II e configuração territorial da Floresta Estadual do Amapá Fonte: Elaboração

O clima da região é do tipo Amw (equatorial super-úmido), com umidade relativa elevada, variando entre 80 e $86 \%$. A temperatura média é $25^{\circ} \mathrm{C}$, com baixa amplitude durante todo o ano. A precipitação anual média na região é de $2.300 \mathrm{~mm}$. (TARDIN et al., 2009). Os solos predominantes são os Latossolo vermelho-amarelos caracterizados por fertilidade natural baixa e saturação de base também baixa. Estes solos são econtrados principalmente nas superfícies de aplainamento que caracterizam a morfoestrutura das colinas do Amapá. 
Além da morfoetrutura das colinas do Amapá a região apresenta também estruturas geomorfológicas dos planaltos residuais do Amapá (Figura 2) sobre formações geológicas da crosta antiga, com predominância de rochas proterozóicas. A área do módulo II da FLOTA está situada no Cráton Amazônico, na província Transamazonas e do domínio Amapá, com ocorrências predominantes de rocha metamórficas, terrenos granulíticos e sequências Vulcano sedimentares com concentrações minerais metálicas diversificadas (BOA VENTURA e NARITA, 1974).

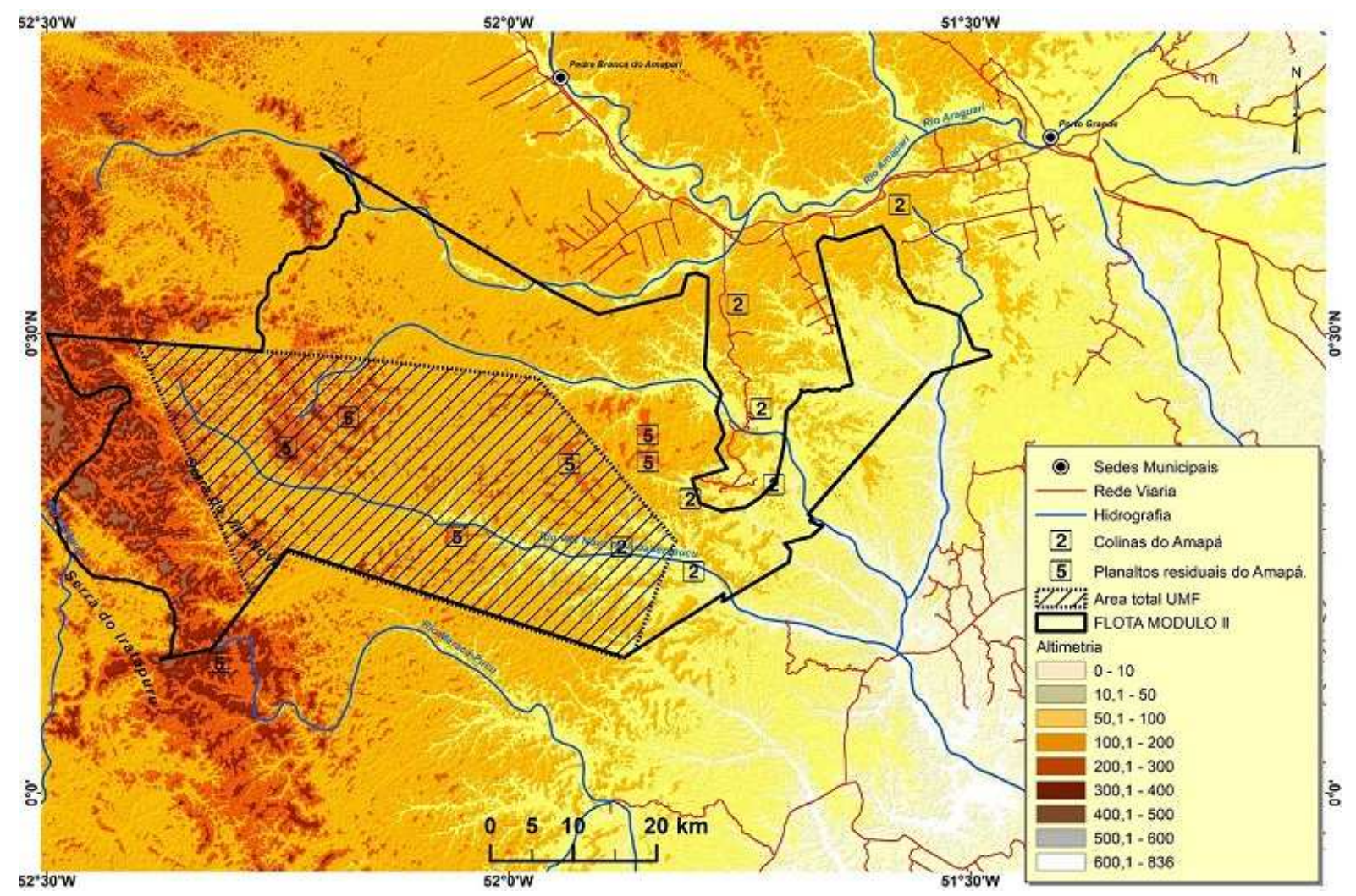

Figura 2. Carta de relevo da área da pesquisa com caracterização das morfoestruturas presentes considerando a classificação de Boa Ventura e Narita (1974).

Fonte: Elaborado com base em mosaico de imagens SRTM fornecido por Miranda et al. (1998).

De acordo com o Instituto Estadual de Florestas do Amapá (IEF) a hidrografia da região é marcada pela ocorrência de centenas de cursos d'água de diversas ordens e extensões . A vegetação predominantemente é a floresta ombrófila densa de baixos platôs (Floresta Ombrófila Densa das Terras Baixas), entremeadas por florestas de terra firme (Floresta Ombrófila Densa submontana), e manchas de Savana (IEF, 2014). Na área Foram registradas 164 espécies madeireiras, sendo 36 consideradas de alto valor comercial e 10 com maior ocorrência na área (Quadro 1). 


\begin{tabular}{|c|l|}
\hline № & Espécies Madeireiras \\
\hline $\mathbf{1}$ & Bowdichia Virgiliodes Kunth. (Sucupira Preta) \\
\hline $\mathbf{2}$ & Cedrela Odorata I. (Cedro-Vermelho) \\
\hline $\mathbf{3}$ & Dinizia Excelsa Ducke (angelim-vermelho) \\
\hline $\mathbf{4}$ & Hymenaea courbaril L. (jatobá) \\
\hline $\mathbf{5}$ & Manikara Huberi (Ducke) A. Chev. (Macaranduba) \\
\hline $\mathbf{6}$ & Diplotropis purpúrea (Rich); Amshoff (Sucupira) \\
\hline $\mathbf{7}$ & Dipteryx odorata (Aubl.)Wild. (Cumarú) \\
\hline $\mathbf{8}$ & Peltogyne paniculata Benth. (Pau-roxo) \\
\hline $\mathbf{9}$ & Handroanthus impetiginosus (Mart. Ex DC.) Matto (ipê-roxo) \\
\hline $\mathbf{1 0}$ & Handroanthus serratifolius (A. H. Gentry) S. Grose (ipê-amarelo) \\
\hline
\end{tabular}

Quadro 1. Espécies Madeireiras de maior ocorrência no Modulo II da FLOTA Fonte: Adaptado de dados do IEF (2014)

\section{Sistemas de engenharias e meio ambiente}

A configuração territorial segundo Santos (1999) é resultado de sistemas de ações e sistemas de objetos que se relacionam. Os sistemas de ações correspondem a toda atividade humana engendrada no meio ambiente. É de se pressupor, que cada sistema de ação, resulta na transformação desse meio ambiente produzindo sistemas de objetos. Os mais variados sistemas de engenharia, como o sistema rodoviário, por exemplo, são, portanto, sistemas de objetos, resultantes de ações que em geral estão relacionadas ao processo de desenvolvimento social e econômico.

Para Santos (2014) por meio ambiente compreende-se "um sistema natural que passa por intensa transformação promovida pela espécie humana e outras espécies que habitam a Terra". A Lei no 6.938, DE 31 DE AGOSTO DE 1981, que dispõe sobre a Política Nacional do Meio Ambiente, em seu Art 3으, Inciso I, define meio ambiente como "o conjunto de condições, leis, influências e interações de ordem física, química e biológica, que permite, abriga e rege a vida em todas as suas formas".

A qualidade ambiental e os riscos constituem-se em uma das mais importantes precauções da sociedade moderna, pois é notório que as consequências desses impactos trazem riscos não só para o meio ambiente, mas também para os seres que nele habitam inclusive o ser humano, e com isso tem ficado cada vez mais evidente a necessidade de a economia caminhar junto com a sociedade e a natureza. Essa percepção tem contribuído para que a legislação de vários países, inclusive o Brasil, avance no caminho do desenvolvimento sustentável e alavanque o surgimento de novas tecnologias (ARAUJO et al., 2013). 
A infraestrutura de transportes é um termômetro da capacidade de um país de garantir com eficácia o processo de desenvolvimento socioeconômico. De igual maneira, a introdução do conceito de sustentabilidade na prática da engenharia é fator importante para fomentar neste processo de desenvolvimento uma economia ecológica como pressuposto para o futuro da economia mundial. Por isso é necessário buscar estudos que encontrem novas tecnologias e sistemas de engenharias para atender essa prática sustentável (NAIME, 2002).

O estudo da infraestrutura de transportes possibilita analisar as técnicas que são empregadas na implantação de rodovias. $O$ atual modelo de tranportes no Brasil é baseado fortemente na rede rodo ferroviário. Esses elementos precisam ser estudados com atenção desde o planejamento, construção até a sua operação. Nesse sentido, os estudos de impacto ambiental possibilitam avaliar de que forma a implantação de uma rodovia pode afetar negativamente ou positivamente uma área.

Em geral durante as obras de implantação de uma rodovia são feitos os acompanhamentos segundo o sistema de gestão ambiental escolhido e a utilização de programas para a diminuição de possíveis consequências negativas referentes à construção. A operação dessa rodovia leva em consideração as técnicas e frequência necessárias à manutenção para que a mesma continue ao longo do tempo tendo eficiência nos fluxos e capacidade de não afetar significativamente o meio de maneira negativa (LAUXEN, 2012).

\subsection{As unidades de Manejo Florestal (UMF) como proposta de desenvolvimento regional}

O Brasil é o país que detém a segunda maior área florestal do mundo, somando cerca de 5,5 milhões de quilômetros quadrados, ou aproximadamente $65 \%$ do seu território. Desse total, 60 \% são de florestas úmidas que ficam na Amazônia legal, no entanto esse valor já foi maior, mas vem a diminuir em consequência do desmatamento ocasionado principalmente pela pecuária e agricultura (SABOGAL et al, 2006).

Embora não seja responsável diretamente pelo desmatamento, a exploração madeireira catalisa a ocupação desordenada e subsequente desmatamento ao financiar, por exemplo, a abertura de estradas não oficiais (VERISSíMO et al., 1995). Entretanto o setor madeireiro colabora significativamente para a economia regional e nacional. Portanto, é preciso encontrar mecanismos que permitam que a exploração madeireira seja feita de forma sustentável, sendo o manejo florestal uma prática bastante adequada para esse fim (SABOGAL et al., 2006). 
O Manejo Florestal Sustentável é uma forma de administração da floresta para a aquisição de benefícios econômicos, sociais e ambientais. O manejo deve primar pelo respeito aos mecanismos de manutenção do ecossistema, considerando-se, cumulativa ou alternativamente, o uso de múltiplas espécies madeireiras, de múltiplos produtos e subprodutos não madeireiros, bem como a utilização de outros bens e serviços florestais (PNGF, 2017).

As Unidades de Manejo Florestal (UMF) são áreas de exploração criadas para prover o manejo florestal primando pela viabilidade ambiental e econômica da utilização direta dos recursos tendo como objetivo fim a conservação da natureza. Nas UMF por meio da produção com sustentabilidade, espera-se propiciar através da participação direta das comunidades locais a melhoria de sua qualidade de vida (IEF, 2014). As UMF devem garantir a permanência dos recursos ambientais e dos processos ecológicos, mantendo a biodiversidade e os demais atributos do ecossistema, de forma socialmente justa e economicamente viável (Lei no 6.938/81, Art 2ㅇ).

\subsection{O relevo como condicionante na implantação da rede rodoviária}

Rodovias são estruturas fixas espaciais complexas que tem como objetivo principal servir como via de transporte terrestre para pessoas e cargas. Entretanto, a implantação e mesmo a manutenção de rodovias pode implicar em impactos negativos ao ambiente se não houver planeamento adequado a cada realidade. A implantação de estruturas de largo alcance como as rodovias impõe grande pressão sobre elementos naturais no território. As adequações no terreno incluem quase sempre alterações no relevo para possibilitar a eficácia das estruturas físicas implantadas pelo homem (CUNHA et al, 2001). No processo de abertura de rodovias as alterações no relevo são realizadas com o objetivo de otimizar o trajeto, fator de agregação de valor necessário ao processo produtivo e que assume importância fundamental no processo definidor dos fluxos sócioeconômicos no território.

O relevo pode ser definido como o conjunto de formas apresentadas na superfície terrestre. Araújo (2017), numa simplificação, afirma que o relevo constitui-se de irregularidades existentes na superfície do planeta. É sobre essa superfície irregular que as obras de engenharia necessárias para a dotação da infraestrutura rodoviária são construídas, causando menor ou maior nível de impacto sobre o relevo e demais elementos que sobre ele interagem. Para Cunha et al. (2001) as estruturas do relevo só podem ser 
compreendidas como resultado de forças endógenas, como a tectônica e exógenas como os processos erosivos atuantes sobre a crosta terrestre.

No Brasil, os relevos dominantes são os planaltos, depressões e planícies, contudo no Amapá, segundo Boa Ventura e Narita (1974) são identificadas 5 unidades morfoestruturais (Quadro 2).

\begin{tabular}{|c|l|}
\hline $\begin{array}{c}\text { UNIDADE } \\
\text { MORFOESTRUTURAL }\end{array}$ & \multicolumn{1}{c|}{ CARACTERÍSTICAS } \\
\hline $\begin{array}{c}\text { Planaltos Residuais do } \\
\text { Amapá }\end{array}$ & $\begin{array}{l}\text { Maciços residuais caracterizados por dissecação fluvial intensa, sob controle } \\
\text { estrutural, dando origem a um conjunto de crista e picos. E formas tabulares, } \\
\text { testemunhos de superfícies de aplainamento mais elevados recobertos por } \\
\text { crosta ferruginosa e/ou manganesífera. As altitudes variam de } 400 \text { a } 550 \text { m. São } \\
\text { constituídos por rochas pré-cambrianas, predominantemente metassedimentos } \\
\text { e vulcânicas ácidas. }\end{array}$ \\
\hline $\begin{array}{c}\text { Planalto Rebaixado da } \\
\text { Amazônia }\end{array}$ & $\begin{array}{l}\text { Planaltos com dissecações produzidas por densidade elevada de drenagens, de } \\
\text { canais curtos e ramificados, formando aplainamentos em colinas de topo } \\
\text { aplainado e interflúvios tabulares. Os terrenos têm altitude média de 100 m. } \\
\text { Essa unidade é constituída por sedimentos terciários da Formação Barreiras. }\end{array}$ \\
\hline $\begin{array}{c}\text { Colinas do Amapá } \\
\text { Planície Fluviomarinha }\end{array}$ & $\begin{array}{l}\text { Predominam formas de colinas com vales encaixados e ravinamentos, são } \\
\text { observados ainda alternância de terraços aluvionares encaixados e faixas } \\
\text { descontínuas, gerando cachoeiras. As altitudes variam de 150 a 200 m. Unidade } \\
\text { resultante da dissecação predominantemente de rochas de Complexo Guianense } \\
\text { e de sedimentos da Formação Barreiras. }\end{array}$ \\
\hline Macapá-Oiapoque & $\begin{array}{l}\text { A evolução da unidade na região do projeto está relacionada aos processos } \\
\text { fluviais da foz do rio Amazonas. São áreas sujeitas a inundações periódicas e com } \\
\text { acréscimo de sedimentos fluviais. }\end{array}$ \\
\hline $\begin{array}{c}\text { Depressão periférica } \\
\text { norte Amazônica }\end{array}$ & $\begin{array}{l}\text { Prolongamento da faixa de circundesnudação periférica à Bacia sedimentar do } \\
\text { Amazonas, limitada pelos planaltos residuais do Amapá ao norte e pelos } \\
\text { rebordos do planalto rebaixado da Amazônia, apresenta altitudes que variam } \\
\text { entre 100 e 150 m. }\end{array}$ \\
\hline
\end{tabular}

Quadro 2. Amapá, caracterização das unidades morfoestruturais

Fonte: Adaptado de Boa ventura e Narita (1974)

\subsection{Elementos de análise no relevo}

Dependendo das características morfoestruturais, a avaliação de impacto deve prover uma análise minuciosa das alterações no relevo, na tentativa de minimizar os impactos dela decorrentes. As unidades morfoestruturais que apresentam feições de considerável grau de declividade no terreno, como é o caso dos planaltos residuais do Amapá, devem, se possível ser evitadas, tanto pelos custos no processo de engenharia, quanto pelos passivos ambientais que eventualmente podem ocorrer (BRASIL, 2010).

A análise do relevo, portanto, é importante para auxiliar no estabelecimento de áreas favoráveis e áreas críticas no processo de implantação da rede rodoviária além de auxiliar na determinação do tipo de traçado mais viável para a sua implantação. É necessário, entretanto levar em conta elementos de análise que proporcionem sistemas de engenharia 
que afetem de forma mínima o meio ambiente, considerando as alterações necessárias no relevo (BANDEIRA, 2004).

O primeiro elemento de análise, então, é a condicionante morfoestrutural. A partir da análise desse elemento é preciso ainda analisar os elementos nela alterados. Dentre aquelas alterações mais significativas no relevo, durante a implantação de rede rodoviária estão os cortes efetuados nas vertentes e a implantação de obras de arte em cursos d'água entre vertentes.

Segundo Cunha et al.(2001) a vertente é uma declividade apresentada pelo morro, montanha ou serra, que pode ser chamada também de encosta e constitui elemento básico e fundamental para o equilíbrio dinâmico do fluxo hídrico superficial. Por isso os cortes realizados para aberturas de rodovias comprometem esses elementos do relevo, afetando em geral extensões regionais. Ademais a desestabilização eventualmente ocasionada pelo revolvimento do solo em grande extensão de corte pode também significar eventuais alterações em cursos d'água e perda do horizonte superficial onde ficam dispostos os principais nutrientes do solo ocasionando impactos com elevados pesos em quesito magnitude e importância (IBGE, 2017).

O corte nas vertentes existentes na estrutura do relevo e a necessidade de implantação de obra de arte (pontes, tubulações etc.) em cursos d'água cortados pelo trajeto da malha viária, por sua vez, relacionam-se a outros impactos, direta ou indiretamente relacionados ao meio físico (BANDEIRA, 2004). Assim, uma metodologia que busque analisar os impactos ambientais causados no meio físico como a alteração do relevo, deve também prover a sua relação com os demais impactos dele decorrentes.

\subsection{Impacto ambiental e avaliação de impacto ambiental}

O termo impacto ambiental é frequentemente relacionado a fatos negativos, notadamente pela vasta cobertura feita pela imprensa aos eventos que causam prejuízos humanos ou materiais decorrentes das alterações no meio ambiente. Em função da acelerada apropriaçao da informação através das redes informacionais os problemas ambientais constituem o foco central em muitos noticiários desde a década de 1990. Foi a partir do final do século XX que ocorreram os primeiros grandes eventos, onde a participação popular 
ganhou força para debater as grandes mudanças ambientais pela qual o planeta está a passar (SÁNCHEZ, 2008).

Segundo o Conselho Nacional de Meio Ambiente (CONAMA), em sua resolução № 001, de 23 de janeiro de 1986, compreende-se como impacto ambiental:

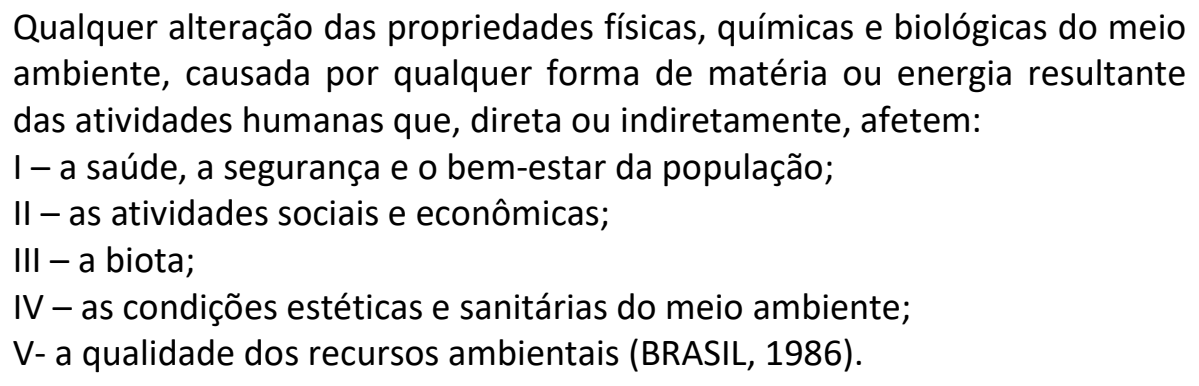
A noção de impacto ambiental estipulada pelo CONAMA pressupõe que qualquer intervenção humana resultante de matéria ou energia aplicada para sua adaptação provoca impacto ambiental direta ou indiretamente. Desta maneira há que se falar que toda ação humana no meio ambiente produz um determinado impacto. A depender de seus desdobramentos esses impactos podem ser positivos ou negativos ao meio biótico, à capacidade de sustentabilidade dos recursos naturais, ao meio físico, e, portanto, à própria condição de existência humana.

Os impactos ambientais, independente de sua importância e magnitude produzem alterações que repercutirão de diferentes formas no ambiente. Pode-se afirmar que os impactos ambientais exibem relação de causa e efeitos em grande medida associados às ações humanas. De fato em algumas ocorrências como é o caso das mudanças climáticas, por exemplo, as ções humanas acentuam os impactos, produzindo efeitos muito indesejáveis (SÁNCHEZ, 2008).

Com a finalidade de equacionar ou mitigar os efeitos ambientais indesejáveis, sugerem-se estudos que visem minimizar ou suprimir impactos negativos ou mesmo potencializar os positivos. Entretanto nem sempre a realização desses estudos foi considerada importante, pois a avaliação dos projetos se restringia a elaboração de Análise de custo-benefício (ACB) e estudos de viabilidade técnica. A expressão avaliação de impacto ambiental (AIA) adentrou na literatura ambiental em 1969 quando foi aprovada pelos Estados Unidos a Lei Federal National Environmental Policy Act (NEPA). Adotado por vários países, esse documento incide em uma política nacional ambiental que tem como ferramenta a avaliação de impactos ambientais (SÁNCHEZ, 2008).

A avaliação de impactos ambientais, em projetos de desenvolvimento regional, tem papel vital na gestão ambiental. Apesar disso, A AIA é considerada como um dos elementos mais 
difíceis e menos compreendido de todo o processo (LAWRENCE, 2007). Por isso o ponto principal no processo de AIA é conseguir a máxima precisão na avaliação enquanto se assegura que os resultados obtidos permaneçam de fácil análise (IJÄS, 2010).

O processo de avaliação ambiental utiliza diversos métodos de análise, como por exemplo, as matrizes de interações, consideradas técnicas bidimensionais, e que permitem associar ações com fatores ambientais. A matriz de interação é uma forma de organizar as informações em uma tabela com eixos, onde em um dos eixos estarão os fatores ambientais e, no outro, as diversas ações realizadas para a implantação de um projeto (SILVA, 2012). Por sua clareza, precisão e simplificação nas análises proporcionadas, a matriz de Leopold, criada em 1971 para o serviço geológico do EUA é entre as matrizes de interação conhecidas, uma das mais utilizadas (FOGLIATTI, 2004).

O princípio básico da matriz de Leopold incide em, primeiramente, assinalar todas as possíveis interações entre as ações e os fatores, para em seguida considerar a magnitude e a importância de cada impacto. Enquanto a valoração da magnitude é em referência objetiva ou normativa, pois se refere ao grau de alteração provocado pela ação sobre o fato ambiental, a pontuação da importância é subjetiva ou empírica uma vez que envolve atribuição de peso relativo ao fator afetado no âmbito do projeto avaliado (COSTA, 2005).

\section{Metodologia}

A avaliação dos impactos ambientais no meio físico foi realizada através do método de sobreposição de cartas tendo como objeto de estudo os impactos causados pela alteração no relevo. Foram sobrepostas as cartas de hidrografia e rede viária sobre a carta de relevo obtida através da composição do mosaico SRTM na escala de 1:250.000 (Miranda et al. 1998). Procurou-se adequar os mapas de resultado considerando a necessidade de análise visual dos elementos do relevo. Além do mapa de caracterização das morfoestruturas do relevo presentes na área da pesquisa, construíram-se ainda dois mapas para análise das alterações no relevo e consequentes impactos provocados por essas alterações durante a implantação da rede viária e na possiblidade de abertura de novas vias.

Foram realizados também levantamentos de campo no entorno do modulo II da FLOTA, com o intuito de caracterizar os sistemas de engenharias que já estão instalados na área. Foram coletados dados do número de vertentes e obras de artes (pontes) existentes. Também registram-se dados de pontos, feições lineares desses elementos ao longo do 
trajeto da rodovia coletora entre a Vila do Cupixi e a Localidade da área da mineração Vila Nova, num percurso de aproximadamente $35 \mathrm{~km}$. Essa rodovia encontra-se dentro da área de entorno do módulo II da FLOTA. O traçado da rodovia modelo no interior da FLOTA foi realizado em SIG, a considerar os elementos de análise de alteração no relevo. Os dados e informações foram tratados nos sistemas de informação geográfica ARCGIS, quantum gis e GV Sig para suporte à análise geográfica e confecção dos mapas relacionados à alteração do relevo e impactos ambientais relacionados.

Como suporte de análise dos impactos ambientais, utilizou-se a matriz de Leopold, essa matriz foi a base para identificar os impactos ao ambiente, levando em consideração o tamanho e a magnitude das implicações ambientais. O preenchimento da matriz foi realizado tomando-se como base o valor máximo dos impactos ambientais para cada item avaliado a partir da alteração no relevo (SILVA, 1994).

A atribuição de pontos foi idealizada segundo metodologia proposta por SANCHEZ (2008) e utilizando a adaptação feita com base em ROCHA (2005), onde se ordena a pontuação conforme a maior importância dos critérios estabelecidos para a magnitude do impacto. Desta forma, à classificação dos impactos mais relevantes é atribuída a maior pontuação. Assim, atribuiu-se uma pontuação para caracterizar as alterações do parâmetro ambiental considerado, objetivando quantificar as alterações ambientais conforme se pode observar nos quadros 3 e 4 .

\begin{tabular}{|c|c|}
\hline \multicolumn{2}{|c|}{ MAGNITUDE = EXTENSÃO + PERIODICIDADE + INTENSIDADE } \\
\hline $\begin{array}{c}\text { EXTENSÃo (Peso: } 1 \text { a 4) } \\
\text { Tamanho da ação ambiental do } \\
\text { empreendimento ou área de influência real }\end{array}$ & $\begin{array}{l}\text { Pequena Extensão (+1) } \\
\text { Média Extensão (+2) } \\
\text { Grande Extensão (+3) } \\
\text { Muito Grande Extensão (+4) }\end{array}$ \\
\hline $\begin{array}{c}\text { PERIODICIDADE (Peso: } 1 \text { a 3) } \\
\text { Duração do efeito da ação; tempo que o efeito } \\
\text { demora a terminar. }\end{array}$ & $\begin{array}{l}\text { Ação temporária (+1): Cessa quando para a ação } \\
\text { Ação variável (+2): Não se sabe quando termina o } \\
\text { efeito após cessar a ação } \\
\text { Ação Permanente (+3): Alta ação impactante }\end{array}$ \\
\hline $\begin{array}{l}\text { INTENSIDADE (Peso: } 1 \text { a 3) } \\
\text { Exuberância da ação impactante; relação da } \\
\text { dimensão a ação com o empreendimento. }\end{array}$ & $\begin{array}{l}\text { Baixa (+1): pequena ação impactante } \\
\text { Média (+2): Média ação impactante } \\
\text { Alta (+3): alta ação impactante }\end{array}$ \\
\hline
\end{tabular}

Quadro 3. Ponderação dos valores (pesos) para os atributos de magnitude Fonte: Adaptado de Rocha et al. (2005) 


\begin{tabular}{|c|c|}
\hline \multicolumn{2}{|c|}{ IMPORTÂNCIA = AÇÃO + IGNIÇÃO + CRITICIDADE } \\
\hline $\begin{array}{l}\text { AÇÃO (Peso: } 1 \text { a } 4 \text { ) } \\
\text { Número de efeitos que a ação } \\
\text { causa }\end{array}$ & $\begin{array}{l}\text { Primária }(+1): 1 \text { causa }=1 \text { efeito } \\
\text { Secundária }(+2): 1 \text { causa }=2 \text { efeitos } \\
\text { Terciária }(+3): 1 \text { causa }=3 \text { efeitos } \\
\text { Enésima }(+4): 1 \text { causa }=n \text { efeitos }\end{array}$ \\
\hline $\begin{array}{l}\text { IGNIÇÃO (Peso: } 1 \text { a 3) } \\
\text { Tempo que a ação leva para } \\
\text { aparecer; é o intervalo de } \\
\text { tempo entre ação e efeito }\end{array}$ & $\begin{array}{l}\text { Imediata (+1): causa=efeito simultâneo } \\
\text { Médio Prazo }(+2) \text { : causa=efeito surge simultâneo e/ou tempo depois } \\
\text { Longo Prazo }(+3) \text { : causa=efeito surge muito tempo depois, } \\
\text { concomitante ou não com os casos anteriores }\end{array}$ \\
\hline $\begin{array}{l}\text { CRITICIDADE (Peso: } 1 \text { a } 3 \text { ) } \\
\text { Nível de relação entre a ação e } \\
\text { o efeito que ela provoca }\end{array}$ & $\begin{array}{l}\text { Baixa }(+1) \text { : baixo nível de ação entre os fatores causa=efeito } \\
\text { Média }(+2) \text { : médio nível de ação entre os fatores causa=efeito } \\
\text { Alta }(+3) \text { : alto nível de ação entre os fatores causa=efeito }\end{array}$ \\
\hline
\end{tabular}

Quadro 4. Ponderação dos valores (Pesos) para os atributos de importância Fonte: Adaptado de Rocha et al. (2005)

A caracterização dos impactos se deu a partir da visão de um grupo de especialistas ligados à Organization for Economic Co-Operation and Development - OECD que propôs indicadores para se avaliar os impactos das estradas florestais no meio ambiente (Quadro $5)$.

\begin{tabular}{|c|c|c|}
\hline $\begin{array}{l}\text { Elementos do } \\
\text { meio ambiente }\end{array}$ & Riscos & Indicadores \\
\hline SOLO & $\begin{array}{l}\text { - Erosão } \\
\text { - Distúrbios litosfera }\end{array}$ & $\begin{array}{l}\text { - Superfície da estrada } \\
\text { - Volume de terra } \\
\text { movimentado } \\
\end{array}$ \\
\hline ÁGUA & $\begin{array}{l}\text { - Redução de infiltração } \\
\text { - Danos às nascentes } \\
\text { - Alteração no escoamento superficial }\end{array}$ & $\begin{array}{l}\text { - Superfície da estrada } \\
\text { - Área drenada } \\
\text { - Destruição de nascentes }\end{array}$ \\
\hline BIOSFERA & $\begin{array}{l}\text { - Redução de habitats } \\
\text { - Fragmentação de habitats }\end{array}$ & - Destruição de habitats \\
\hline RECURSOS NATURAIS & $\begin{array}{c}\text { - Degradação dos recursos } \\
\text { não-renováveis } \\
\text { - Perda de espaço para plantio }\end{array}$ & $\begin{array}{l}\text { - Volume extraído } \\
\text { - Área perturbada }\end{array}$ \\
\hline
\end{tabular}

Quadro 5. Indicadores para a avaliação de impactos ambientais de estradas florestais Fonte: Adaptado de OECD (2006) 


\section{Elementos de análise no relevo: identificação do número de pontos alterados, avaliação e caracterização dos impactos relacionados}

A partir da observação da sobreposição das cartas de hidrografia e rede viária sobre a carta de relevo e do levantamento de dados obtidos em campo foi possível identificar o número de pontos de impactos relacionados aos cortes nas vertentes e obras de arte em curso d'água (Pontes e tubulões de concreto). Com base na identificação dos pontos alterados foi possível avaliar e caracterizar os impactos ambientais deles decorrentes. Segundo a NBR ISO 14004/96, uma vez definidos os impactos ambientais, é necessário determinar sua importância ou significância. "A importância de cada impacto ambiental identificado pode variar de uma organização para outra. A quantificação pode auxiliar no julgamento."

\subsection{Alterações nos elementos do relevo na Rodovia Coletora implantada entre a Vila} de Cupixi e a Área de exploração mineral do rio Vila Nova e análise de impactos ambientais relacionados

A partir da Localidade de Cupixi, as margens da BR 210, foi implantada uma rodovia coletora. Essa rodovia com aproximadamente $35 \mathrm{~km}$ de extensão corre sobre o relevo das colinas do Amapá em altitudes que variam entre 50 e 200 metros (Figura 3).

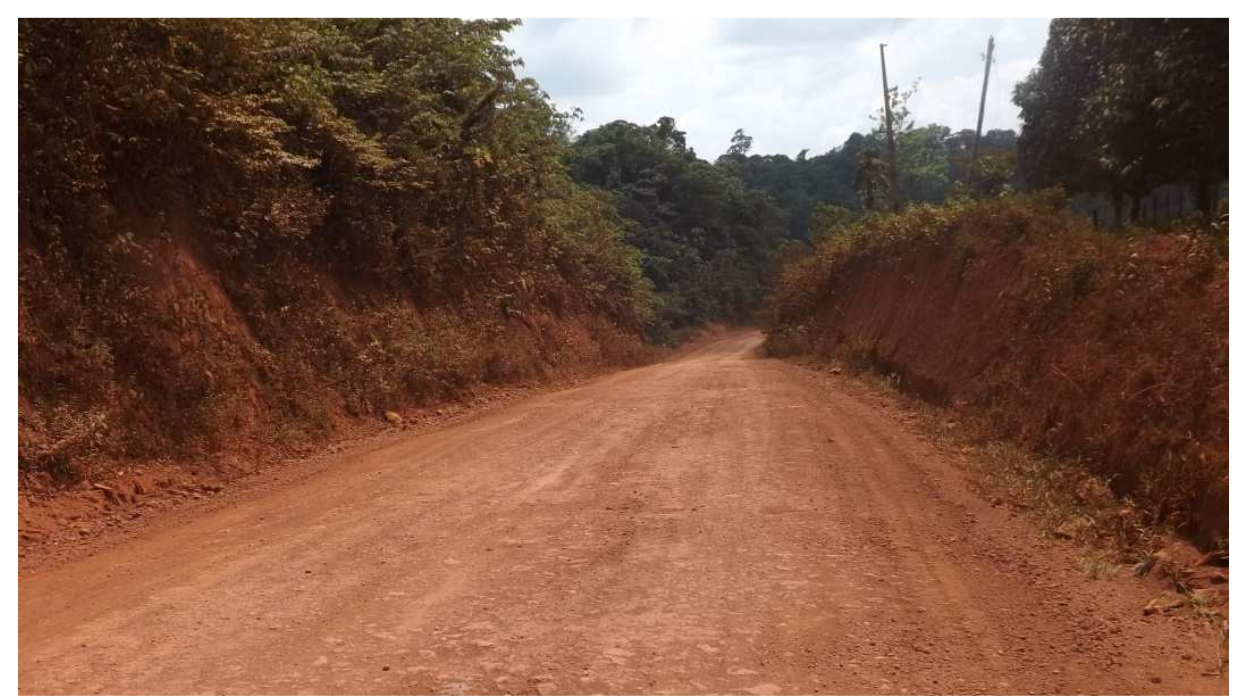

Figura 3. Corte na vertente em trecho da rodovia Cupixi-Vila Nova no entorno do módulo II da FLOTA 
Ao longo do trajeto, a rodovia Cupixi-Vila Nova apresenta 27 cortes em vertentes e 9 obras de artes (Pontes e tubulões) em cursos d'água,sobre altimetrias com variações abruptas (Figura 4).

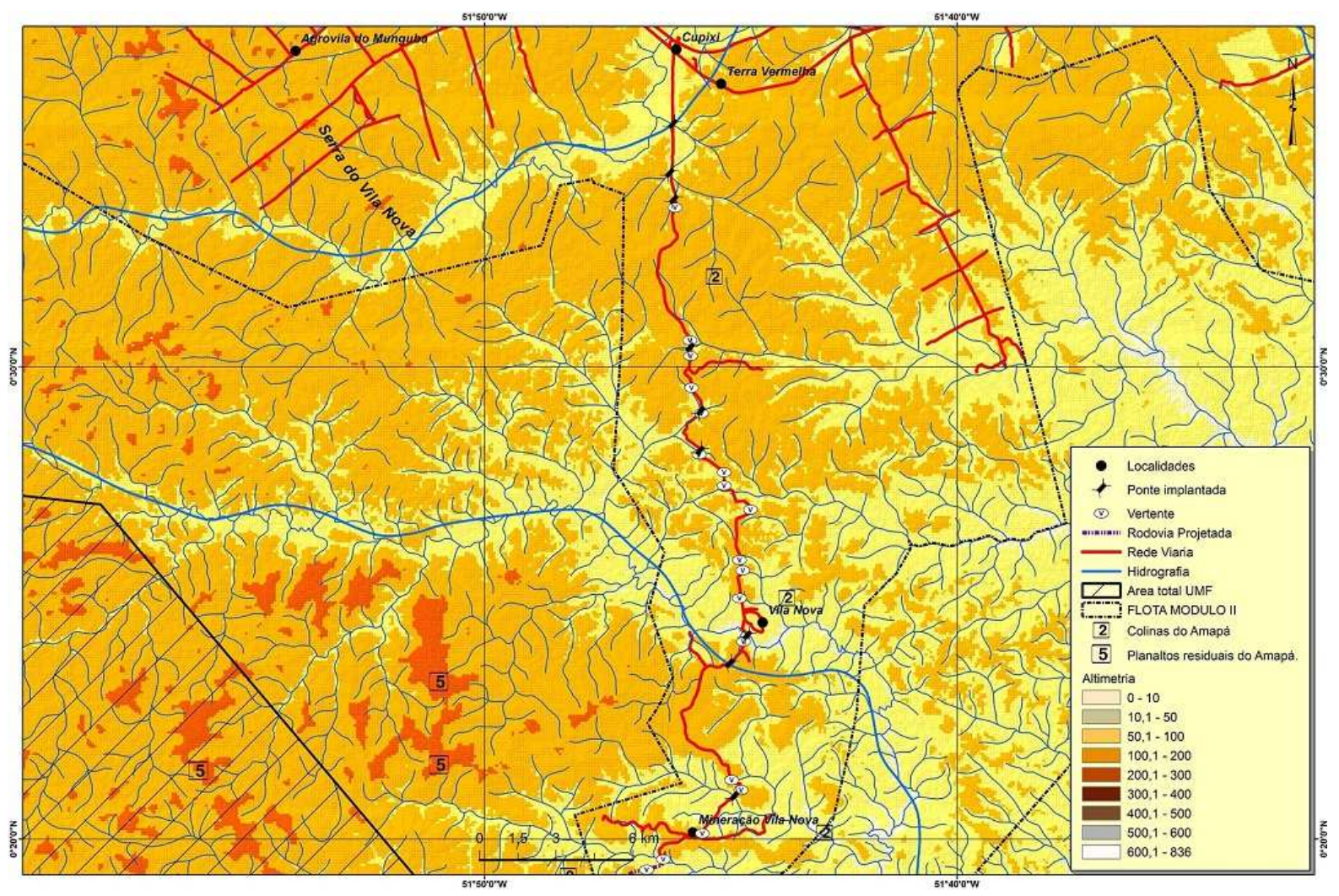

Figura 4. Carta de relevo com cortes nas vertentes e obras de artes na rodovia Cupixi-Vila Nova no entorno do modulo II da FLOTA

Fonte: Elaborado com base em mosaico de imagens SRTM fornecido por Miranda et al. (1998)

Portanto com a caracterização dos impactos, foi possível identificar a magnitude e importância de cada um, onde para cada elemento de análise valorou-se um peso levando em consideração os quadros de ponderações dos valores (Quadros 3 e 4), de forma a classifica-los por critérios significativos, ou seja, de que forma esse impacto, afeta o meio, em que intensidade isso ocorre e com qual magnitude. Sendo dentro desses aspectos levado em consideração alguns fatores, tais como: extensão, periodicidade, intensidade, ação, ignição e criticidade. Esses dados foram dispostos e organizados na Matriz de Leopold representada no quadro 6 . 


\begin{tabular}{|c|c|c|c|c|c|c|c|c|}
\hline \multicolumn{9}{|c|}{ ELEMENTOS DE ANÁLISE PARA IMPACTOS CAUSADOS POR ALTERACAO NO RELEVO } \\
\hline \multirow{2}{*}{\multicolumn{2}{|c|}{$\begin{array}{l}\text { Número de Pontos do } \\
\text { relevo alterado com }\end{array}$}} & \multirow[b]{2}{*}{ Impactos relacionados } & \multicolumn{3}{|c|}{$\begin{array}{l}\text { Magnitude do } \\
\text { impacto }\end{array}$} & \multicolumn{3}{|c|}{ Importância } \\
\hline & & & ז̊ & $\begin{array}{l}\frac{0}{0} \\
\frac{\pi}{0} \\
\frac{0}{4}\end{array}$ & $\begin{array}{l}\frac{0}{0} \\
\frac{\pi}{0}\end{array}$ & 20 & $\stackrel{0}{2 \pi}$ & $\frac{2}{\frac{\pi}{0}}$ \\
\hline \multirow{4}{*}{$\begin{array}{l}\text { Cortes na } \\
\text { vertente }\end{array}$} & \multirow{4}{*}{27} & Supressão vegetal; & 3 & 3 & 2 & 4 & 1 & 3 \\
\hline & & $\begin{array}{l}\text { Interferência no escoamento } \\
\text { superficial; }\end{array}$ & 4 & 3 & 2 & 2 & 2 & 1 \\
\hline & & Interferência na infiltração; & 4 & 3 & 2 & 2 & 2 & 1 \\
\hline & & Processos erosivos. & 4 & 3 & 3 & 4 & 2 & 2 \\
\hline \multirow{4}{*}{$\begin{array}{c}\text { Obras de arte } \\
\text { em curso } \\
\text { d'água }\end{array}$} & \multirow{4}{*}{9} & $\begin{array}{c}\text { Processos erosivos nas } \\
\text { cabeceiras; }\end{array}$ & 3 & 2 & 3 & 4 & 2 & 2 \\
\hline & & Contaminação da água, & 4 & 2 & 3 & 4 & 2 & 2 \\
\hline & & Supressão vegetal. & 2 & 1 & 2 & 4 & 1 & 3 \\
\hline & & Alteração do fluxo hídrico & 4 & 2 & 2 & 3 & 3 & 2 \\
\hline
\end{tabular}

Quadro 6. Matriz de impactos com ponderação dos valores (pesos) de magnitude e importância a partir da alteração no relevo para estrada de entorno (conformidade com a Matriz de Leopold.).

Fonte: Elaboração

A partir da sobreposição das cartas de hidrografia e rede viária sobre a carte de relevo e de dados de confirmação em campo identificaram-se 27 pontos de alteração do relevo com cortes na vertente. Esses cortes produziram quatro tipos de impactos com magnitudes e importância que variam do peso 1 ao 4 . As alterações no relevo produzidas pela implantação de obras de arte (Pontes e tubulões de concreto) também produziram 4 tipos de impactos com pesos que também variam entre 1 e 4 . Com base na valoração de pesos feitas na tabela 1 foi possível descrever e avaliar cada impacto segundo a ponderação de valores relacionada.

\subsubsection{Impactos relacionados aos cortes nas vertentes}

\section{Supressão vegetal}

Impacto negativo, com média magnitude; de grande extensão da ação ambiental; considerado um impacto permanente com média intensidade. Importância moderada, onde o número de efeitos que a ação causa é considerada enésima provocando efeitos, a ignição é imediata, a criticidade é alta. É um impacto irreversível, mas permite compensação.

Interferência no escoamento superficial 
Impacto negativo, direto, permanente e irreversível. Sua ocorrência é certa e imediata, a partir do início dos trabalhos de movimentação de terra. Pela grande extensão das áreas afetadas, apresenta grande magnitude, com alta relevância e significância.

\section{Interferência na infiltração}

Impacto negativo, permanente, de média intensidade, com magnitude média, ação secundária e tem baixa criticidade, podendo ser compensado com projetos de drenagem eficientes.

\section{Processos erosivos}

Impacto negativo, de grande extensão e manifestação imediata, desde o inicio dos processos de terraplanagem e revolvimento do solo, é de alta ação impactante por consequência de sedimentos soltos que com a ajuda do escoamento superficial, são carreados para os cursos d'água provocando alteração da qualidade da água e fluxo do rio. Pode causar diversos efeitos, mas pode ser revertido dependendo do grau da erosão.

\subsubsection{Impactos relacionados a obras de arte em curso d'água}

Quando considerando a ação de obras de arte (nesse caso, pontes) no curso d'água, observando o número de pontos e onde estão instaladas é possível inferir que haverá alteração nos fluxos de água nos pontos impactados. A amplitude desses impactos, entretanto, só poderia ser avaliada com mais eficácia com algum monitoramento dos históricos das médias de vazão, por exemplo. Mas, o meio hídrico é diretamente afetado por essa ação, havendo ainda a modificação da paisagem como um todo, fragilizando as margens adjacentes e aumentando o risco de erosão e assoreamento.

\section{Processos erosivos nas cabeceiras das obras de arte (cabeças de ponte)}

Impacto negativo, de grande extensão, com alta ação impactante, onde o número de efeitos é enésima, ignição de médio prazo, e criticidade média, pois é um impacto que pode ser retido.

\section{Contaminação da água}

Impacto negativo, indireto, de alta magnitude (haja visto o número de obras de artes feitas nos rios), de importância significativa, de média duração (com caráter esporádico, se cessar a fonte de contaminação e recuperar a qualidade da água), reversível, mitigável e evitável. 


\section{Supressão vegetal}

Impacto negativo, de média extensão, cessa quando para a ação, média magnitude. Capacidade de retenção do escoamento superficial e carreamento de resíduos sólidos para o rio.

\section{Alteração do fluxo hídrico}

Impacto negativo, com grande extensão, não se sabendo quando o impacto pode cessar após término da ação, com média ação impactante, longo tempo de duração e médio nível de criticidade.

\subsection{Esboço de projeto geométrico de uma rodovia para acesso as UMFs do módulo II} da FLOTA utilizando sobreposição de cartas de relevo e Matriz de Leopold para simular as alterações no relevo e impactos ambientais relacionados

O trajeto proposto no projeto geométrico de estrada leva em consideração o prolongamento da estrada já existente na área da Mineração Vila Nova. Esse trajeto partiria do ramal da área mineralizada sul, a cortar um curso d'água de quarta ordem, tributário da margem direita do rio Vila Nova. O percurso, com aproximadamente $22 \mathrm{~km}$, corre sobre as Colinas do Amapá, em altitudes que variam entre 50 e 200 metros procurando cortes mais contínuos entre os 100 e 200 metros a fim de minimizar a inclinação e o consequente corte do terreno para adequação do terrapleno ao relevo. Apesar disso o traçado do projeto apresenta 12 pontos em que o corte do relevo é realizado em vertentes (Figura 5, pontos V).

$\mathrm{Na}$ altura do km 12 a partir do ponto inicial do percurso projetado, a estrada corta um curso d'água de quarta ordem, tributário da margem esquerda do rio Anauerapucu do Vila Nova, sendo este o único trecho em que seria necessário a impactação direta de um curso d'água para a implantação de obra de arte. Tais dados podem ser observados na figura 5. 


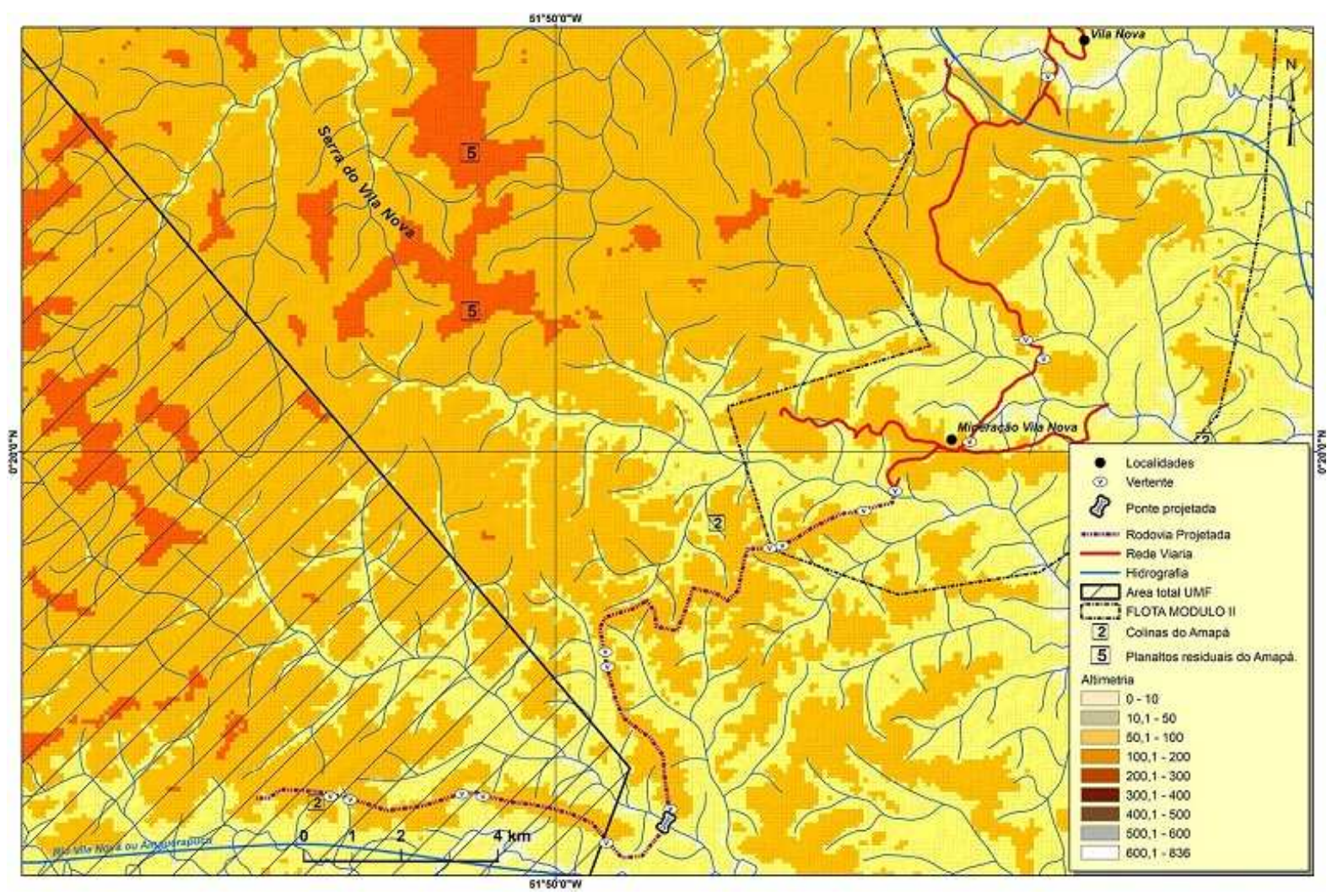

Figura 5. Carta de relevo com esboço do projeto geométrico de rodovia (modelo) para acesso ás UMF do modulo II da FLOTA

Fonte: Elaborado com base em mosaico de imagens SRTM fornecido por Miranda et al. (1998)

Neste caso foram considerados os mesmo possíveis impactos que podem ser gerados se a estrada vier a ser construída levando em consideração o relevo como condicionante, no entanto diferente da estrada já construída no entorno da área foco, esse trajeto projetado como modelo considerou diversos fatores descartado na estrada anterior, manteve uma atenção para a diminuição dos cortes nas vertentes, ocasionando assim uma minimização na magnitude e importância dos impactos, contando ainda com a preocupação na construção de obras de artes (Pontes) em curso d'água, que como pode ser observado na carta de relevo diminui drasticamente o número de pontes em relação à estrada já construída, isso porque a cada corte e a cada obra de arte construída uma nova área é afetada de forma significativamente. No entanto, mesmo com a projeção desses traçados é possível que ocorra impactos ambientais na área, mas menos significativos do que da estrada observada anteriormente.

Tal como na estrada de entorno, para o modelo também se realizou a identificação da magnitude e importância para cada impacto, atribuindo valores a partir da relação desses impactos com a sua causa, considerando os elementos de análise da Matriz de impactos (quadro 7). 


\begin{tabular}{|c|c|c|c|c|c|c|c|c|}
\hline \multicolumn{9}{|c|}{ ELEMENTOS DE ANÁLISE PARA IMPACTOS CAUSADOS POR ALTERACAO NO RELEVO } \\
\hline \multirow{2}{*}{\multicolumn{2}{|c|}{$\begin{array}{l}\text { Número de Pontos de } \\
\text { impacto com }\end{array}$}} & \multirow[b]{2}{*}{ Impactos relacionados } & \multicolumn{3}{|c|}{ Magnitude do impacto } & \multicolumn{3}{|c|}{ Importância } \\
\hline & & & $\underset{\substack{0 \\
0}}{20}$ & $\begin{array}{l}\frac{0}{0} \\
\frac{\pi}{0} \\
\frac{0}{0} \\
\frac{0}{0}\end{array}$ & $\begin{array}{l}\frac{0}{0} \\
\frac{\pi}{0} \\
\frac{\pi}{n}\end{array}$ & i⿱乛龰心 & 宽 & $\begin{array}{l}\frac{0}{0} \\
\frac{\pi}{0} \\
\frac{0}{4}\end{array}$ \\
\hline \multirow{4}{*}{$\begin{array}{l}\text { Cortes na } \\
\text { vertente }\end{array}$} & \multirow{4}{*}{12} & Supressão vegetal; & 2 & 1 & 2 & 4 & 1 & 3 \\
\hline & & $\begin{array}{l}\text { Interferência no escoamento } \\
\text { superficial; }\end{array}$ & 2 & 2 & 2 & 2 & 2 & 2 \\
\hline & & Interferência na infiltração; & 2 & 2 & 2 & 2 & 2 & 2 \\
\hline & & Processos erosivos. & 2 & 2 & 2 & 3 & 2 & 3 \\
\hline \multirow{4}{*}{$\begin{array}{l}\text { Obras de arte } \\
\text { em curso } \\
\text { d'água }\end{array}$} & \multirow{4}{*}{1} & $\begin{array}{c}\text { Processos erosivos nas } \\
\text { cabeceiras; }\end{array}$ & 2 & 2 & 2 & 2 & 2 & 3 \\
\hline & & Contaminação da água, & 2 & 2 & 2 & 4 & 3 & 2 \\
\hline & & Supressão vegetal. & 1 & 1 & 1 & 4 & 1 & 3 \\
\hline & & Alteração do fluxo hídrico & 2 & 2 & 2 & 3 & 3 & 2 \\
\hline
\end{tabular}

Quadro 7. Matriz de impactos com ponderação dos valores (pesos) para estrada projetada Fonte: Elaboração

Os impactos foram detalhados a seguir de forma individual, levando em consideração a tabela 7 em conformidade com a Matriz de Leopold.

\subsubsection{Impactos relacionados a cortes na vertente}

\section{Supressão vegetal}

Impacto continua apresentando caráter negativo, mas com média extensão da ação ambiental; por necessidade de deixar a área da rodovia descoberta é considerado um impacto permanente com média intensidade. Importância moderada, onde o número de efeitos que a ação causa é considerada enésima provocando $n$ efeitos, a ignição é imediata, a criticidade é média. É um impacto irreversível na área da rodovia, mas na borda e encosta pode haver reflorestamento permitindo compensação.

\section{Interferência no escoamento superficial}

Impacto tem caráter negativo, com média extensão, intensidade média e importância média, podendo ser reversível com a implantação de projetos de drenagem.

\section{Interferência na infiltração}

Impacto negativo, com média magnitude e média importância, podendo ser minimizado com projetos de drenagem, tal como no impacto relacionado ao escoamento superficial. 


\section{Processos erosivos}

Impacto negativo, com magnitude média e importância média, como foi considerado o relevo durante a formulação do traçado, os cortes na vertente foi diminuído, ocasionando na minimização de processos erosivos.

\subsubsection{Impactos relacionados a obras de arte em curso d'água}

\section{Processos erosivos nas cabeceiras}

Impacto negativo, com magnitude e importância de caráter mediano devido ao número reduzido de obras de arte em cursos d'água (Totalizando apenas um).

\section{Contaminação da água}

Impacto negativo, indireto, de baixa magnitude, de importância não significativa, dada as formas de controle e número de obras implantadas (Sendo apenas uma), de curta duração (com caráter esporádico, se cessar a fonte de contaminação e recuperar a qualidade da água), reversível, mitigável e evitável.

\section{Supressão vegetal}

Impacto negativo, mas considerado de baixa magnitude por apresentar apenas uma obra de arte, tem média importância, pois a supressão da vegetação continua afetando de diversas formas o rio.

\section{Alteração do fluxo hídrico}

Impacto negativo, indireto, de baixa magnitude e importância não significativa em consequência do número de obras implantadas (Sendo apenas uma), de curta duração (com caráter esporádico, se cessar a fonte de contaminação e recuperar a qualidade da água), reversível, mitigável e evitável.

Os impactos apresentados na Matriz de Leopold (Tabela 6) elaborada para a estrada de entorno entram em consonância com a situação observada por Guerra et al. (1998) que expõem os problemas de desgaste do relevo associado à precariedade de investimentos em uma infraestrutura mais sustentável das rodovias BR - 010 e BR - 222.

Dentre os impactos identificados e avaliados na estrada de entorno da FLOTA, a supressão vegetal e os processos erosivos são os que mais apresentam relação com os demais impactos, pois a partir deles outras implicações ambientais maximizam, constituindo criticidade ambiental de alto teor para a área. Malinovski e Perdoncini (1990) afirmam que a construção de estradas florestais significa grande perda de áreas de vegetação e fragilidade no solo, isso porque, após a supressão vegetal o solo fica exposto, ampliando o grau de fragmentação florestal e diminuindo a quantidade de interceptores naturais da precipitação que é feita pela capa florística. Essa supressão vegetal interfere também no escoamento superficial diminuindo a capacidade de infiltração da área pelo aumento de liquido sobre o 
solo pela perda de raízes vegetais. Quanto ao processo erosivo o revolvimento do solo o deixa mais frágil e com isso suscetível a erosão e desprendimento de sedimentos que podem ser carreados pelo escoamento superficial até os mananciais hídricos.

Com o traçado da rodovia modelo, a partir do prolongamento da estrada que está implantada no entorno do modulo II da FLOTA, foram analisados as alterações no relevo. Na criação da rodovia modelo estipulou-se a alteração do relevo como condicionante ambiental, desta maneira, os impactos causados foram minimizados em sua magnitude e importância. O modelo proposto provou que com um planejamento adequado a implantação de rodovias pode ser realizada de forma a otimizar os custos sociais, econômicos e ambientais. Entretanto, embora sejam tomadas medidas preventivas, sempre haverá impactos negativos.

\section{Considerações finais}

Com base nas ponderações a partir da matriz de Leopold foi possível analisar as alterações nos elementos alterados do relevo, procurando avaliar e comparar magnitude e importância para cada rodovia estudada. A pesquisa auxiliou ainda a compreender fatores históricos relacionados ao processo de implantação da rodovia que fica entre a vila de Cupixi e a área de exploração mineral do rio Vila Nova.

O pioneirimso amapaense de exploração mineral em escala industrial acabou por estabelecer alguns padrões de apropriação e uso do solo rural cuja dinâmica inicia-se com a abertura de pequenas rodoviais coletoras, ou como são mais comumentes chamadas "ramais". A abertura dessas rodovias se baseava na procura pela eficiência do acesso para uso comercial. Essa forma de implantação, de certa maneira, privilegia o desenvolvimento econômico regional em detrimento de sua eficácia social e ambiental. Com isso observou-se que as alterações no relevo no caso específico da rodovia implantada no entorno do módulo II da FLOTA apresentam um número de cortes nas vertentes e obras de arte a causar impactos ambientais de magnitude e importância de grande valor.

A apropriação das florestas nas Unidades de Manejo Florestal no módulo II da FLOTA, ainda não foi efetivada. O processo de exploração pressupõe a abertura de novas vias para acesso e escoamento da madeira a ser retirada, pois os cursos d'agua interiores em seus altos cursos, não permitem a navegabilidade. Portanto a analise de como essa estrada poderá afetar o meio se for construída com base nas preocupações ambientais é de suma importância.

A avaliação da magnitude e importância dos impactos causados pela alteração do relevo na estrada do entorno do Módulo II da FLOTA indica um traçado pouco eficaz para a mitigação de impactos. Percebe-se que as obras de engenharia rodoviária causaram mais impactos do 
que aqueles que seriam eventualmente provocados pelo modelo de projeto geométrico estipulado na pesquisa. Esse modelo possibilitou realizar um traçado que aproveitou a continuidade altimétrica e buscou minimizar as alterações no relevo, diminundo-se o número de cortes entre vertentes a fim de mitigar os impactos ambientais.

Recomenda-se que a implantação de novas rodovias na área do Módulo II da FLOTA visando o escoamento dos produtos florestais, considere um traçado que permita diminuir o número de cortes entre vertentes privilegiando áreas mais homogêneas do relevo planáltico das colinas do Amapá. De igual maneira, esse traçado deve, sempre que possível, evitar a transposição de cursos d'água. As formações dos planaltos residuais do Amapá no interior da Unidade de Conservação são responsáveis pelas nascentes de muitos cursos d'água, dentre os quais o rio Vila Nova, de grande volume e que forma importante bacia hidrográfica a desaguar no Amazonas, a sudeste do estado.

A eficiência ambiental de uma rodovia está diretamente relacionada a um processo produtivo que alie um transporte eficaz da produção e respeito às demandas sociais e ambientais de maneira a possiblitar um desenvolvimento regional sustentável. A aplicação de metodologias para avaliação prévia de impacto ambiental de rodovias pode ser um passo importante para auxiliar na mitigação dos impactos negativos e potencialização dos positivos na atividade extrativa florestal, que no Amapá, é fortemenete atrelada ao transporte rodoviário.

\section{Referências bibliográficas}

ARAUJO, F.; BEZERRA, I.; PINTO, J.; VASCONCELOS, M.; PESSOA, T.; SILVA, T. A engenharia a serviço da ética, sociedade e meio ambiente - Recife: UPE/POLI, 2013

ARAUJO, G. Tipos de relevo do Brasil. Disponível em: http://www.estudopratico.com.br/tipos-de-relevo-dobrasil. acesso em 07 de abril 2017.

BANDEIRA, C.; PAGEL, E. Avaliação de impacto ambiental de rodovias, Caderno Didático no 8, 1a ed./ Clarice Bandeira, Eduardo P. Floriano. Santa Rosa, 2004.

BRASIL. Departamento Nacional de Infraestrutura de Transportes. Diretoria Executiva. Instituto de Pesquisas Rodoviárias. Diretrizes básicas para elaboração de estudos e projetos rodoviários: instruções para acompanhamento e análise. - Rio de Janeiro, 2010.564p. (IPR. Publ. 739).

BRASIL. Resolução CONAMA № 001, Brasília de 23 de janeiro de 1986.

BOAVENTURA, F.; NARITA C. Folha NA/NB. 22-Macapá - II Geomorfologia. In: Brasil. Projeto RADAM. Folha NA/NB.22-Macapá; geologia,geomorfologia,solos,vegetação e usos potenciais da terra (Levantamento dos Recursos Naturais,6) . Rio de Janeiro,1974.

COSMO, P. Relatório sem reversão patrimonial dos bens da ICOMI. 2007. Disponível em: <http://icomi.blogspot.com.br>. Acesso em 08 de abril 2017.

COSTA, M.V.; CHAVES, P.S.V. \& OLIVEIRA, F.C. Uso das Técnicas de Avaliação de Impacto Ambiental em Estudos Realizados no Ceará. In: XXVIII Congresso Brasileiro de Ciências da Comunicação, Anais INTERCON, Rio de Janeiro, 2005. 
CUNHA, S.B.; GUERRA, A.J.T. (org.). Impactos ambientais urbanos no Brasil. Rio de Janeiro: Bertrand Brasil, 2001.

FOGLIATTI, M.C.; FILIPPO, S. e GOUDARD, B. Avaliação de Impactos Ambientais: aplicação aos sistemas de transporte. Rio de Janeiro: Interciência, 2004.

GUERRA, A. J.T.; COELHO, M. C. N.; MARÇAL, M. dos S. Açailândia, Cidade Ameaçada pela Erosão. Ciência Hoje, Rio de Janeiro, v. 23, n. 138, p. 36-45, 1998.

IBGE - Instituto Brasileiro de Geografia e Estatística. Noções Básicas de Cartografia. Disponível em: <https://www.ibge.gov.br/home/geociencias/cartografia/manual_nocoes/elementos_representacao.html>. Acesso em: 14 de abril de 2017.

IEF - Instituto Estadual de Florestas do Amapá. Plano de Manejo da Floresta Estadual do Amapá. Macapá, 2014.

IJÄS, A.; KUITUNEN, M.T. \& JALAVA, K. Developing the RIAM method (rapid impact assessment matrix) in the context of impact significance assessment. Environmental Impact Assessment Review Vol. 30, p. 82-89, 2010.

LAUXEN, M. A mitigação dos impactos de rodovias sobre a fauna: Um guia de procedimentos para tomada de decisão. Porto Alegre, 2012.

LAWRENCE D.P. Impact significance determination - back to basics. Environ Impact Asses Rev, Vol.27, p. 75569, 2007.

MALINOVSKI, J. R.; PERDONCINI, W. Estradas de uso florestal. Colégio Florestal de Irati - GTZ. Irati, 1990.

MIRANDA, E.E.; CAPUTI, E.; FERREIRA, A.S. Caracterização dos padrões espaciais e temporais das queimadas na Amazônia Legal. Embrapa Monitoramento por Satélite, 1998.

NAIME, Roberto. Impacto ambiental em estradas - Impacto ambiental das obras civis. Porto Alegre, 2002.

OECD - ORGANIZATION FOR ECONOMIC CO-OPERATION AND DEVELOPMENT. Applying Strategic Environmental Assessment: good practice guidance for development co-operation. Paris: OECD, 2006.

PNGF - Portal Nacional de Gestão de Florestas. Manejo Florestal: Apresentação. Disponível em:< http://www.florestal.gov.br/pngf/manejo-florestal/apresentacao>. Acesso em 05 de fevereiro de 2017.

PORTO, J. L. R.; GUIMARAES, D. C.; TOSTES, J. A.. Dinâmicas espaciais e urbanas amapaenses. In: Anais do XIV Encontro Nacional de Geógrafos. Rio Branco, 2006.

ROCHA, J.S.M.; GARCIA, S.M.; ATAIDES, P.R.V. (2005) Manual de avaliações de impactos e passivos ambientais. Santa Maria: Ed. Palloti. 479 p.

SABOGAL, C.; POKORNY, M.; SILVA, J.; VERÍSSIMO, J.; BOSCOLO, M. Manejo florestal empresarial na Amazônia brasileira: Restrições e Oportunidades. Relatório Síntese.Belém, 2006

SÁNCHEZ, Luiz Enrique. Avaliação de impacto ambiental - conceitos e métodos. - São Paulo: oficina de textos, 2008.

SANTOS, Milton. A natureza do espaço: técnica e tempo, razão e emoção. 3. ed. São Paulo: Hucitec, 1999.

SANTOS, J.; IMBERNON, R. A concepção sobre "natureza" e "meio ambiente" para distintos atores sociais. São Paulo/SP, 2014.

SILVA, O. ; CUNHA, L. Sistema viário e dinâmicas produtivas pioneiras na porção leste da Amazônia setentrional brasileira. Cadernos de Geografia, vol III, no 35. Universidade de Coimbra: Coimbra, 2016.

SILVA, E. Avaliação qualitativa de impactos ambientais do reflorestamento no Brasil. Viçosa, MG: UFV, 1994.

SILVA, A.; MORAES, J. Proposta de uma matriz para avaliação de impactos ambientais em uma indústria plástica. Bento Gonçalves-RS, 2012

TARDIN, A. T.; RABELO, B. V.; FACUNDES, F. S.; ALMEIDA, J. C.; ÁVILA, J. E. S.; LOBATO JUNIOR, J. P. A.; PICANÇO, J. R. A.; SILVA, L. M. S.; GUEDES, L. A. C.; OLIVEIRA, M. R. M.; DIAS, M. C. S.; MELO, R. M. S.; FERREIRA, T. J. M. Plano de recuperação do Pa Nova Canaã. Porto Grande, 2009.

VERÍSSIMO, A.; BARRETO, P.; TARIFA, R. \& Uhl, C. Extraction of a high-value natural resource from Amazon: the case of mahogany. Forest Ecology and Management 72: 39-60, 1995. 